\title{
Kalman's last decade: Passive network synthesis
}

\author{
Malcolm C. Smith (mcs@eng.cam.ac.uk) \\ November 30, 2016
}

The Art Nouveau splendour of Budapest's Hotel Gellért was the scene for a fascinating day in July 2010. The focal point of the discussions was the classical theory of passive network synthesis - a beautiful subject that reached its zenith around 1960, only to decline steadily thereafter as an active research interest, and yet a subject that still raises many deep and intriguing questions. Widening conversations and a special session at the Mathematical Theory of Networks and Systems conference in the following days led the late Uwe Helmke to organise and host a workshop on Network Synthesis in September of that year in Würzburg (see Figures 1 and 2), which initiated an inspirational series of meetings that has alternated with Cambridge. What was the origin of Kalman's intense interest in this topic?

It was in 2004, while browsing his reprint collection, that Kalman was taken back to this subject that had fascinated him in his graduate student days at MIT. The paper that caught his eye [1] — by the great pioneer of network synthesis R.M. Foster—contained intriguing claims that appeared to rest on the elaborate calculations of an unpublished Master's thesis by Foster's last student E.L. Ladenheim [2]. Acquisition of the manuscript did not solve the mystery. The thesis is essentially a catalog of the 108 "generic" RLC networks with at most two reactive elements and at most 3 resistors. Formulas are given for the impedance parameters in terms of network parameters (straightforward) and vice versa (not at all straightforward). Crucially, no proofs are provided.

This chance encounter with Foster's paper turned into the major scientific interest of Kalman's last decade - one that would break the sequence of the previous three decades of research. This began in the mid 1970s with work on the partial realisation problem of covariance sequences, moving on to econometrics and the Reiersol problem in the 1980s, and then to random sequences, volatility, and risk in financial markets in the 1990s. It was the apparently moribund subject of passive network synthesis that took Kalman still further back to one of his great contributions in the first decade of his research, and to a fascination with algebraic invariant theoy that arose in the second. 
The surprising fact that led to our meeting in the Hotel Gellért in 2010 was that we Ladenheim thesis, which until then had only one citation - the above-mentioned reference in [1]. 
What has been very striking in my own interactions with Rudy Kalman during the last six years was the enormous curiosity and intellectual energy he displayed, and his purposefulness to articulate big ideas and connections. No better example of this can be found than his remarks on Foster's Reactance Theorem in [6], which he came to regard on a par with Newton's gravitational law, "but in Foster's case linking the man-made real world of engineering with mathematics". Frequent e-mails and conjectures on network synthesis in these last years were supported by abundant hand computations, and extensive, eclectic reading in science, mathematics and literature. All this was in the context of a very real generosity that he showed to me and my students. Even in his last months, with his health collapsing, he wrote to me expressing his determination to attend and speak at the 4th Workshop on Mathematical Aspects of Network Synthesis in Cambridge, held in September 2016. Sadly it was not to be and it became my task to present a memorial lecture for him, discussing his ideas, which are his greatest legacy.

The majority of Kalman's seminal papers were written in the first decade of his research. Nevertheless his influence throughout his career has been immense. This is equally true of his work in the last decade. It is very fitting to conclude with his own words: "Much remains to be done. But the Promised Land has been sighted from several directions" [6].

\section{References}

[1] R.M. Foster, "Academic and theoretical aspects of circuit theory," in Proc. IRE, vol. 50, May 1962, pp. 866-871.

[2] E.L. Ladenheim, "A synthesis of biquadratic impedances," Master's thesis, Polytechnic Inst. of Brooklyn, N. Y., 1948.

[3] J.Z. Jiang and M.C. Smith, "Regular Positive-Real Functions and Five-Element Network Synthesis for Electrical and Mechanical Networks", IEEE Trans. on Automat. Contr, vol. 56, 2011, pp. 1275-1290.

[4] R. Kalman, Private communication (e-mail to S. Pincus copied to the author, 6 Nov. 2014).

[5] R. Kalman, Algebraic Invariant Theory in Systems Research (Lecture 1), Proceedings of the 21st MTNS, July 7-11, 2014, Groningen.

[6] R. Kalman, "Old and new directions of research in system theory," LCNIS vol. 398, Springer, 2010, pp. 3-13, Eds: J. C. Willems, S. Hara, Y. Ohta, and H. Fujioka.

[7] T.H. Hughes and M.C. Smith, "Algebraic criteria for circuit realisations", Mathematical System Theory, Eds: Knut Hüper and Jochen Trumpf, CreateSpace, 2013, pp. 211-228. 


\section{Author Biography}

Malcolm C. Smith (M90 SM00 F02) was educated at the University of Cambridge. After several years in Germany, Canada, and the USA, he returned to Cambridge, where he is currently

4 Professor and Head of the Control Group. He is a Fellow of the Royal Academy of Engineering. 


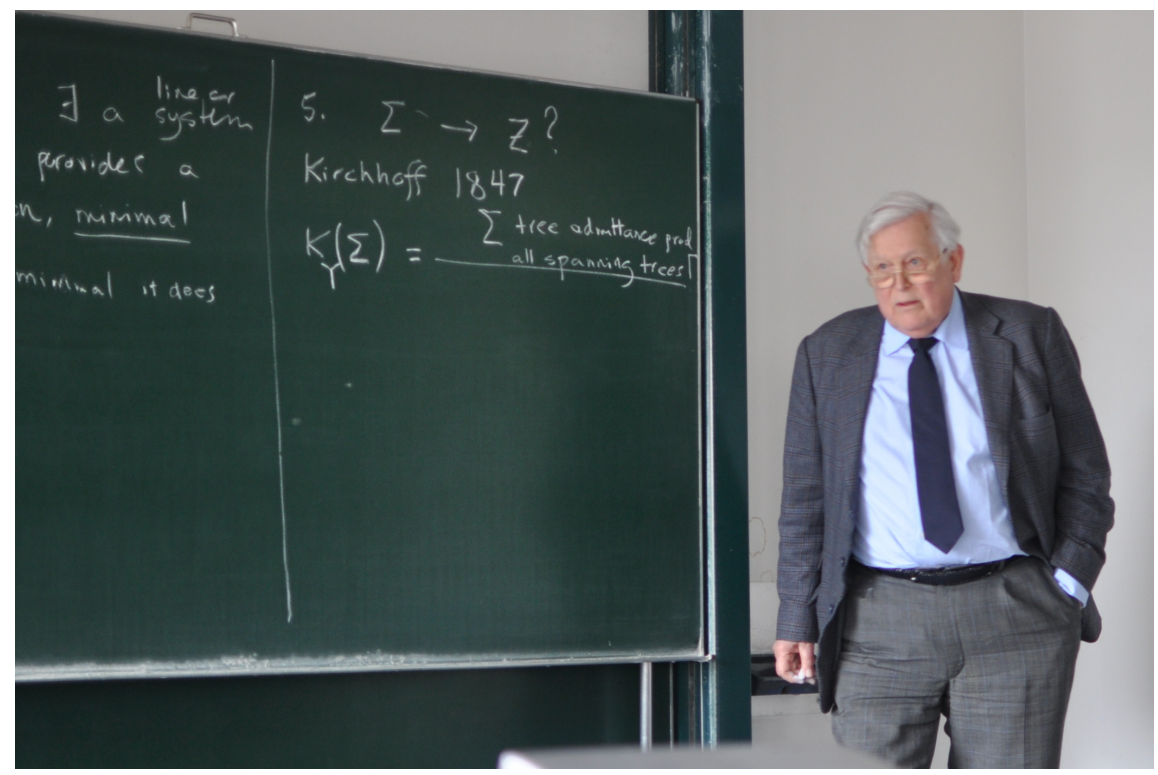

Figure 1. Kalman's lecture on 27 September 2010 at the workshop on Mathematical Aspects of Network Synthesis, Würzburg.

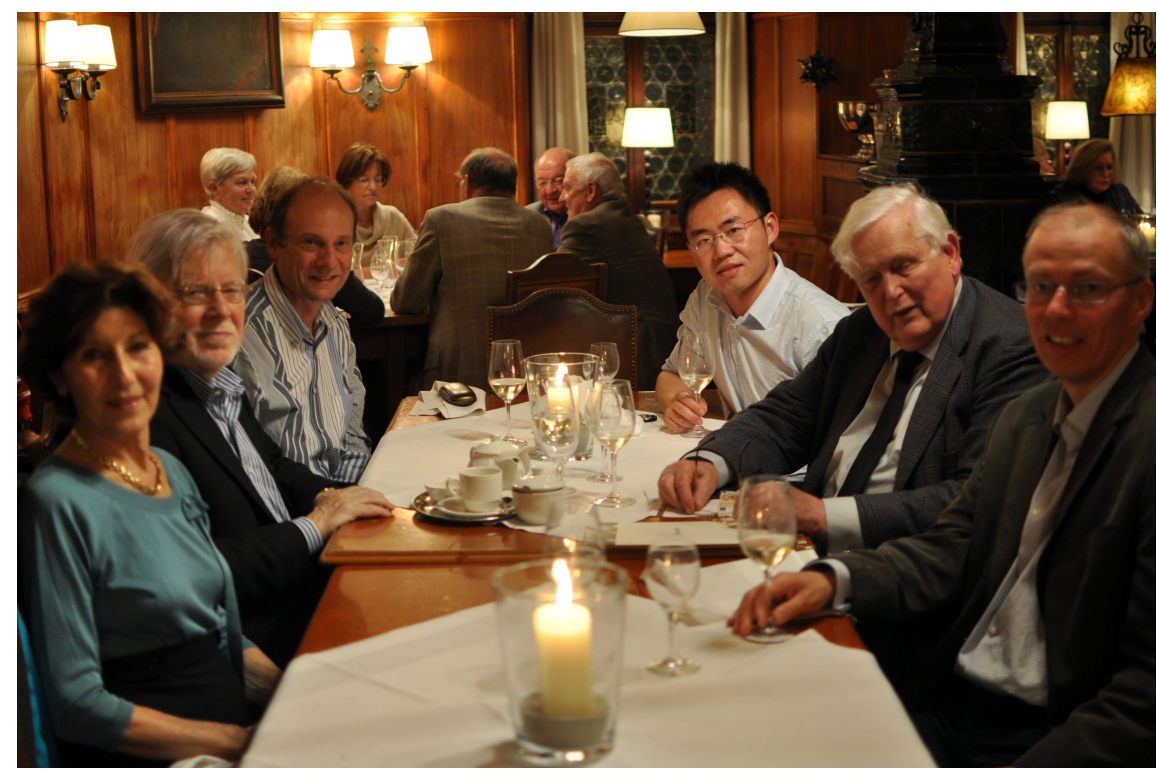

Figure 2. Workshop dinner in Würzburg, September 2010 (left to right): Dina Kalman, Jan Willems, Uwe Helmke, Jason Jiang, Rudy Kalman, Malcolm Smith. 